\title{
Confounding variables affecting long term results of standard two screw cephalomedullary nail in intertrochanteric fractures of femur
}

\author{
Rajeev Shukla1, Adhir Jain', Pranav Mahajan²*, Ravikant Jain ${ }^{1}$
}

\begin{abstract}
${ }^{1}$ Department of Orthopaedics, Sri Aurobindo Medical College and PG Institute, Indore, Madhya Pradesh, India ${ }^{2}$ Department of Orthopaedics, MGM Medical College and MY Hospital, Indore, Madhya Pradesh, India
\end{abstract}

Received: 26 October 2020

Revised: 04 December 2020

Accepted: 05 December 2020

\author{
*Correspondence: \\ Dr. Pranav Mahajan, \\ E-mail: pranav.mahajan@gmail.com
}

Copyright: (C) the author(s), publisher and licensee Medip Academy. This is an open-access article distributed under the terms of the Creative Commons Attribution Non-Commercial License, which permits unrestricted non-commercial use, distribution, and reproduction in any medium, provided the original work is properly cited.

\begin{abstract}
Background: Inter trochanteric fractures of femur are common fractures in the elderly. The aim of the study was to assess the long-term functional outcome of patients treated with trochanteric fixation nail (TFN) for inter trochanteric femur fractures and to determine variables which affect the final outcome of surgery at the end of five years.

Methods: The study was done at tertiary centre in central India with 152 patients who sustained intertrochanteric femur fracture. The patients were followed up at 6 weeks, 6 months, 1 year, 2 years and 5 years after the surgery. The assessment of pain, functional activity, walking ability and range of motion were assessed by Harris hip score at 6 months, 1 year, 2 years and 5 years.

Results: The good/excellent outcome at the end of 5 years was found in $84 \%$ of cases. Patients with age less than 65 years and male patients had better outcome at the end of five years. Some of the complications encountered with this type of implant were $\mathrm{z}$ effect, delayed union, screw back-out/breakage, varus collapse which affected the final outcome. Conclusions: TFN is effective treatment technique for inter trochanteric fractures of femur worldwide. There are some complications which can occur with this type of implant in early post-operative period but still long-term follow-up of patients suggested that the fracture pattern, preoperative mobility status, timing of surgery, post op mobilization also plays a key role in determining functional outcome of patients.
\end{abstract}

Keywords: Inter-trochanteric hip fractures, Trochanteric fixation nail, Functional outcome

\section{INTRODUCTION}

Inter trochanteric fracture of femur is one of the most common injuries occurring in elderly population all over the world. The most common mode of injury in older age group is trivial trauma like a slip or fall while in the younger age group, it is mostly due to high velocity trauma like road traffic accidents. The complications can occur in all age groups depending on the type of injury, severity of injury and include malunion, implant failure, screw cutout/breakage, $\mathrm{z}$ effect, reverse $\mathrm{z}$ effect etc.
Most of the studies have observed that more than $50 \%$ of inter trochanteric femur fractures coming to hospitals are unstable fractures. According to Knobe et al all the fractures of intertrochanteric femur with absence of medial calcar support, separation of lesser trochanter, fracture involving greater trochanter or broken lateral wall will be considered unstable. ${ }^{1}$ All the patients having osteoporosis and who have sustained inter trochanteric femur fracture have a poor prognostic factor because fixation of the proximal fracture fragment depends entirely on the quality of cancellous bone. 
The calcar forms the major load bearing area in the proximal femur. ${ }^{2}$ The extramedullary implant like the dynamic hip screw plates have a biomechanical drawback in comparison to intramedullary implants (load sharing device). TFN has a shorter lever arm and the distance between the hip joint and the nail is reduced as compared to that of an extramedullary implant resulting in weakening of distorting forces across the implant. ${ }^{3}$ Fracture instability and osteoporosis are associated with a higher risk of complications and poor outcomes. ${ }^{4}$ The purpose of all the surgeries in modern day practice is to start early mobilization and the implant which provides best stability in these fractures should be used. It also helps in reducing the morbidity and mortality in these cases.

There are many implant choices available to the surgeon for treating inter trochanteric femur fractures but still cephalomedullary nail with two screws is the most widely accepted and used implant. All the implants have their advantages and disadvantages. This study was taken up to assess the patients operated for intertrochanteric femur fracture using TFN over a period of five years and determine the factors which affect the functional outcome like type of fracture, quality of bone. We also assessed the intra operative and post-operative complications like mechanical failures, technical complications etc. while using this implant.

The objective of the study was to assess the outcome of TFN in stable and unstable inter trochanteric femur fractures in adult age group, determine the complications associated with the procedure and assess the factors which are important for better post-operative functional outcome.

\section{METHODS}

This study was an observational prospective cohort study performed from January 2010 to February 2019 at our hospital (Sri Aurobindo medical college and post graduate institute, Indore, Madhya Pradesh, India) which is a tertiary care center. All the patients coming to the OPD and emergency who sustained fracture inter trochanteric femur fracture were considered to be a part of the study. Patients with any other associated fractures, compound injuries and pathological fractures were excluded from the study. All the patients who accepted to be a part of the study were explained the details of the study and written consent taken from them.

Patients with age more than 40 years, no associated fractures in either of the lower limbs, closed fractures, open grade 1 fractures were included in the study while patients less than 40 years of age, patients who sustained other fractures in either of the lower limbs, patients with open fractures (grade 2 and 3) were excluded from the study.

We included 152 patients who had inter trochanteric femur fracture and were managed using two screw TFN. All the patients underwent routine clinical and radiographic examination. The fractures were classified according to AO classification for proximal femoral fractures (Figure 2). ${ }^{5}$ After complete pre anesthetic work up and prior fitness, all the patients underwent closed /open reduction internal fixation using TFN under regional anesthesia over fracture table. The same team of surgeons operated upon the patients included in the study. All the surgeons had surgical experience of more than five years.

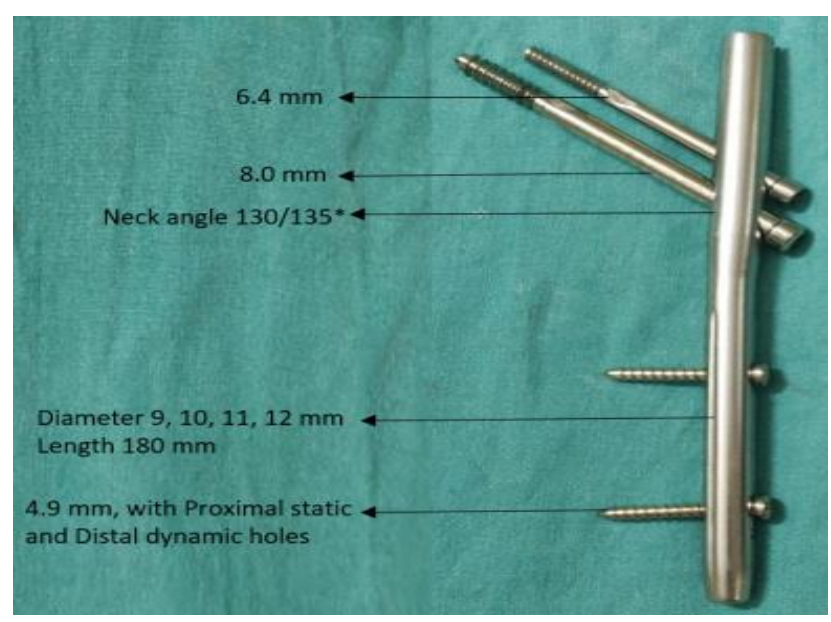

Figure 1: Trochanteric fixation nail (TFN).

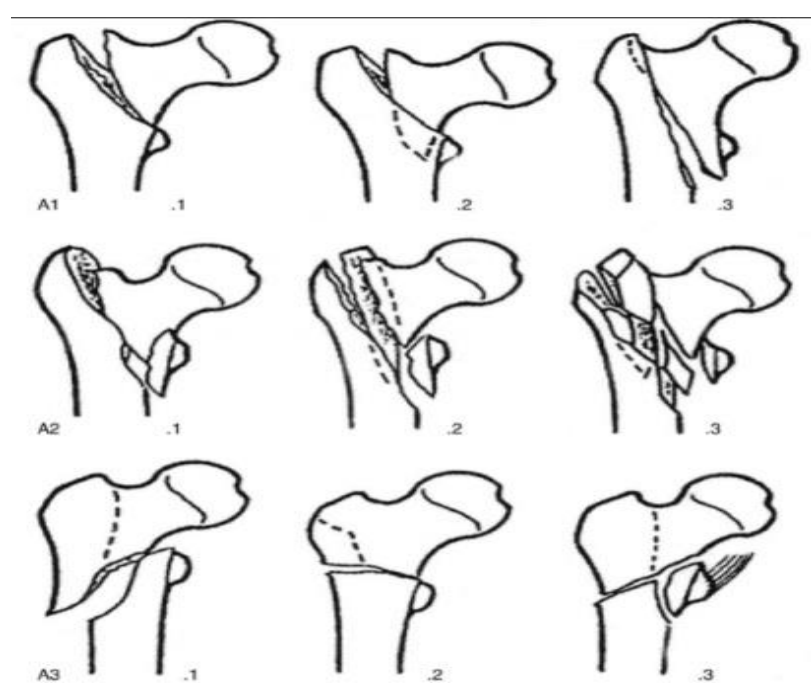

Figure 2: AO classification of inter trochanteric femur fractures.

Fracture reduction was checked under c-arm image intensifier guidance (Allengers HF $49 \mathrm{R}$ ) in both coronal and sagittal planes. Under all aseptic precautions, painting and draping was done. Incision was given at the level of greater trochanter and extended proximally for $5 \mathrm{~cm}$. Entry is made using a curved awl. Guide wire is passed inside the canal. Entry point is widened using canal opener. Reaming is done in gradually increasing sizes. Nail size is identified and inserted using zig. Proximal and distal screws of appropriate sizes were fizzed. The reduction was confirmed under c-arm guidance, then zig is removed. Wound wash and closure are done. 
All patients were given injectable antibiotics in the form of third generation cephalosporin for 3 days followed by oral antibiotic for next 5 days. Deep venous thrombosis (DVT) prophylaxis with low molecular weight heparin/rivaroxaban were given for a minimum of 3-4 weeks prophylactically. Patients were allowed high-sitting on bed, static and dynamic quadriceps exercises, ankle movement and active toe movement exercises on the first post-operative day. Suture removal was done at 2 weeks. Patients were mobilized non-weight bearing to partial weight bearing with walker support as soon as the pain subsided and general condition permitted. Full weight bearing was started carefully depending on the stability of the fracture and adequacy of fixation, delaying it for 6-8 weeks, for patients with unstable or inadequate fixation. In clinical or proven osteoporotic patients, additional de rotation bar was applied for 21 days to prevent loss of reduction. All the patients were followed up for a period of 5 years.

\section{Evaluation criteria}

The assessment of pain, functional activity, walking ability and range of motion were assessed using Harris hip score. ${ }^{6}$ All the complications occurring in patients were recorded like delayed union, infection, screw cut-out, z effect, screw back out.

Patients were followed-up at 6-weeks, 3 months, 6 months, 1 year, 2 years and at 5 years post-operatively.

\section{Calculation}

All the data were analysed using SPSS 22.0. The scores at 6 months, 1 year, 2 years and 5 years final follow-up were compared using two-sided paired sample t-test. Score in different age groups and gender were compared using Student's t-test. The $\mathrm{p}$ value $<0.05$ was considered as significant.

\section{RESULTS}

A total 152 study patients were included with mean age of $72.78 \pm 9.19$ years (Range-45-90 years) with 42 males and 110 females. As per AO classification, 62 patients were A1 type, 68 patients A2 type, 22 patients were A3 type (Table 1 ). Average operating time was $57 \pm 15$ (minutes). Left sided involvement was in 94 patients and right sided involvement was in 58 patients (Table 2).

Table 1: Age wise distribution.

\begin{tabular}{|lll|}
\hline Age (Year) & Number & Percent $(\%)$ \\
\hline$<\mathbf{6 5}$ & 21 & 13.81 \\
\hline $\mathbf{6 5 - 7 5}$ & 72 & 47.36 \\
\hline $\mathbf{7 5 - 9 0}$ & 59 & 38.81 \\
\hline Mean & $72.78 \pm 9.19$ & \\
\hline Range & $45-90$ & \\
\hline
\end{tabular}

Table 2: Patient demographics.

\begin{tabular}{|c|c|c|}
\hline Demographics & \multicolumn{2}{|c|}{ Variables } \\
\hline Age (years) & \multicolumn{2}{|c|}{ Mean $72.78 \pm 9.19$} \\
\hline Gender (\%) & \multicolumn{2}{|c|}{$\begin{array}{l}\text { Male-42 }(27.63) \\
\text { Female-110 (72.3) }\end{array}$} \\
\hline Side $(\%)$ & \multicolumn{2}{|c|}{$\begin{array}{l}\text { Left-94 (61.8) } \\
\text { Right-58 (38.2) }\end{array}$} \\
\hline Mode of injury (\%) & \multicolumn{2}{|c|}{$\begin{array}{l}\text { Trivial trauma-128 (84.2) } \\
\text { RTA-24 (15.8) }\end{array}$} \\
\hline $\begin{array}{l}\text { Average operative } \\
\text { time (min) }\end{array}$ & \multicolumn{2}{|l|}{$57 \pm 15$} \\
\hline AO type & Number & $\begin{array}{l}\text { Percentage } \\
(\%)\end{array}$ \\
\hline A1 & 62 & 40.8 \\
\hline $\mathbf{A} 2$ & 68 & 44.7 \\
\hline A3 & 22 & 14.5 \\
\hline Total & 152 & 100 \\
\hline $\begin{array}{l}\text { Abbreviation: RTA: } \\
\text { Arbeitsgemeinschaftfür } \\
\text { Internal Fixation) }\end{array}$ & $\begin{array}{l}\text { road tra } \\
\text { Osteosynthes }\end{array}$ & $\begin{array}{l}\text { accident; } \\
\text { gen (Society }\end{array}$ \\
\hline
\end{tabular}

Out of the total patients included in the study, eight patients required extended incision with opening of fracture site since one or two of the fracture fragments were unstable even in traction and were not allowing proper reduction. In all the patients, soft tissue impingement was found which was cleared and fragments held in place using clamps.

Good/excellent results were found in $84 \%$ of cases (Figure 3 ). There was improvement in pain, functional activities, walking ability and range of motion at five years when compared with six months which may be due to better muscle strength by the end of five years (Table 3 ).

The average Harris hip score at six months follow up was $79.65 \pm 9.38$, it was $83.54 \pm 7.59$ at the end of one year, $86.14 \pm 8.42$ at the end of two years and $88.70 \pm 7.56$ at the end of five years (Table 3 ).

Final functional outcome for AO type A1 was 92.50 \pm 2.43 , $86.21 \pm 3.58$ for type A2 (Figure 3 ) and $75.76 \pm 8.81$ for type A3 fractures which shows that final outcome is relatively better in stable fractures as compared to unstable fractures (Table 4).

It was observed that patients who were active and mobile pre operatively were found to have better post-operative outcome at the end of five years. Those patients who were home bound or bed ridden pre operatively had less Harris hip score at the end of five years.

Out of the total 152 patients, twenty-six patients were known case of hypertension and thirty-eight patients were known case of diabetes mellitus. Out of these, thirteen patients had both hypertension and diabetes both. All the patients were operated after strict control of blood pressure and blood sugar levels prior to surgery. 


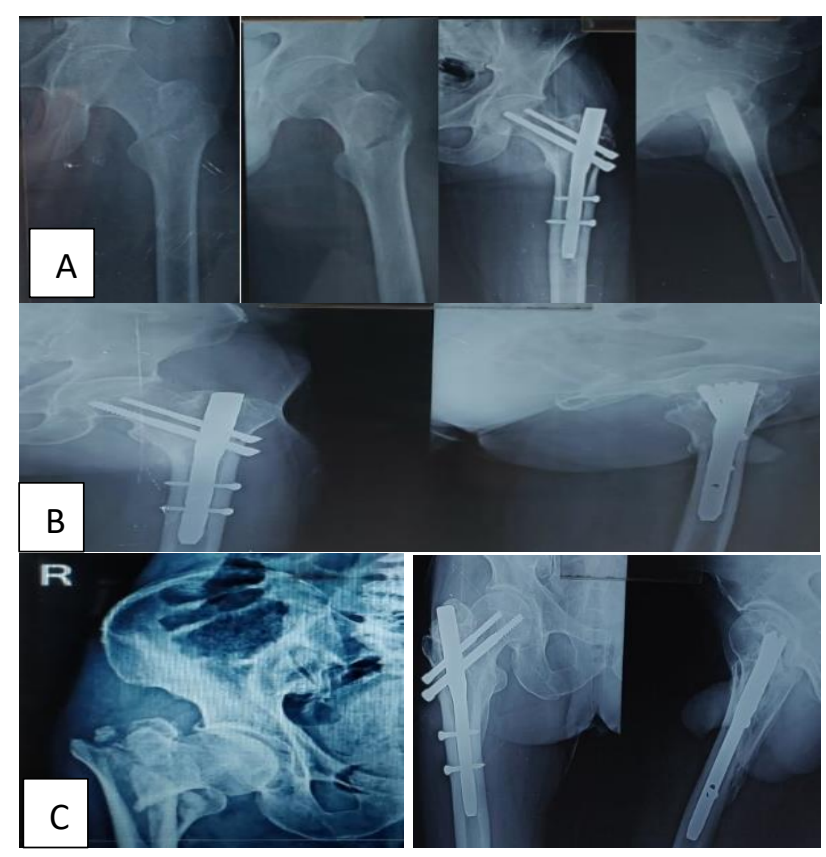

Figure 3: Radiographs of TFN used in the AO (A) type 1, (B) type 2, (C) type 3 fracture with excellent score at final follow up of 5 years post-operatively.

Out of the total 152 patients, twenty-six patients were known case of hypertension and thirty-eight patients were known case of diabetes mellitus. Out of these, thirteen patients had both hypertension and diabetes both. All the patients were operated after strict control of blood pressure and blood sugar levels prior to surgery.

Complications occurred in nine patients $(5.92 \%)$ including one surgical site infection, two screw breakage/cut-out, one $\mathrm{z}$ effect, two with fascia-lata pain/screw back out, one with varus collapse, one with mal-union, one with delayed union (Table 5).

One patient developed surgical site infection at around two weeks post operatively. He was 71-year male patient, a known case of diabetes mellitus with uncontrolled sugar level at the time of injury. He was started with insulin prior to surgery. He had A3 type fracture requiring longer operating time of 72 minutes. Since there was frank pus discharge at the time of suture removal, patient was taken for debridement and thorough lavage. Pus culture showed growth of methicillin resistant staphylococcus aureus sensitive to linezolid and clindamycin. Patient was given intravenous antibiotics for three weeks followed by three weeks of oral antibiotics. He recovered completely by the end of 6 weeks.

There were two patients who had screw back-out and fascia-lata pain. One patient was 74-year-old female, obese with osteoporotic bone. She came for follow up at six weeks. On follow up $\mathrm{X}$ ray, proximal screw $(8 \mathrm{~mm})$ back out was found. The patient was taken for reexploration and screw was changed to a smaller size screw.
Patient was kept non-weight bearing for three weeks. She had good follow up score at the end of five years.

Another patient who was 75-year-old male, known hypertensive, non-compliant patient, started full weight bearing mobilization at home after discharge, was lost to follow up. He came to OPD at 3 months post op. The proximal screws were palpable on clinical examination. On getting his X-ray, back-out of proximal screws was seen with loss of reduction. This patient underwent implant removal followed by hemi-arthroplasty (Figure 4).

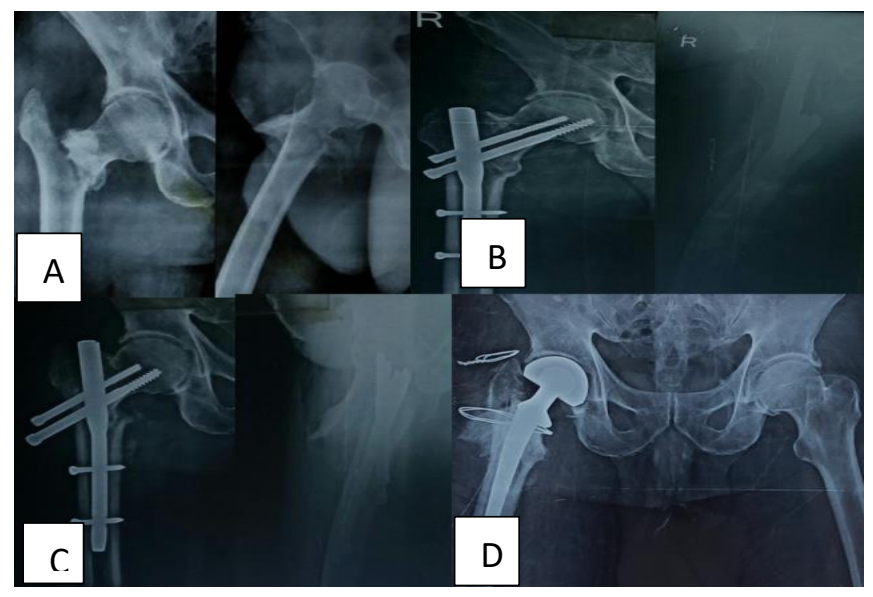

Figure 4: Radiograph of AO type A3 Fracture (A) TFN at immediate post-operative (B) back-out of proximal screws with reduction loss $(C)$ implant removal done followed by hemiarthroplasty (D).

One patient, 65-year female, osteoporotic who had AO A2 Type fracture who underwent surgery came to follow up at 4 weeks and was diagnosed to have medial migration of superior lag screw and lateral migration of inferior lag screw at four weeks post operatively i.e., z effect (Figure 5 A). Patient underwent revision surgery and delayed union occurred.

Two patients, one 64-year male and other 70-year female came to follow up at 2 months with pain in hips region after the patient started mobilization. On getting their Xray, they were diagnosed to have screw cut-out/breakage inside the bone. Both of these patients were re-operated with implant removal and hemi-arthroplasty was done using Bipolar hemi prosthesis (Figure $5 \mathrm{~B}$ ). Patient tolerated the procedure well and started mobilization with good result at 5 years follow up. Both of these patients were given bisphosphonates in the form of monthly ibandronate for a period of one year along with calcium and vitamin d supplements.

One of the rare intra operative complications occurred in 48-year male patient who underwent surgery. While drilling over the guide wire for proximal screw, the drill bit was not going inside smoothly and the guide wire was getting pushed towards the acetabulum. On removing the drill outside, it was found that guide wire was broken inside (Figure $5 \mathrm{C}$ ). The guide wire was removed with the 
help of instruments used in laparoscopic surgery. The proximal screws of nail were tightly fixed. Patient tolerated the procedure well and later on came with good outcome.
It was also found that complications were common in patients who didn't follow the post-operative rehab protocol properly.

Table 3: Harris hip score at each follow up.

\begin{tabular}{|llllll|}
\hline Variables & At 6 month & At 1 year & At 2 year & At 5 year & P value \\
\hline Pain & $36.32 \pm 5.24$ & $37.52 \pm 4.50$ & $38.33 \pm 3.30$ & $39.22 \pm 3.12$ & 0.0001 \\
\hline $\begin{array}{l}\text { Functional } \\
\text { Activities }\end{array}$ & $8.81 \pm 1.56$ & $9.61 \pm 1.24$ & $10.32 \pm 2.83$ & $11.03 \pm 2.05$ & 0.0001 \\
\hline $\begin{array}{l}\text { Walking } \\
\text { Ability }\end{array}$ & $27.32 \pm 1.78$ & $28.31 \pm 1.10$ & $29.24 \pm 1.71$ & $30.02 \pm 2.15$ & 0.0001 \\
\hline $\begin{array}{l}\text { Range of } \\
\text { Motion }\end{array}$ & $7.20 \pm 0.80$ & $8.10 \pm 0.75$ & $8.25 \pm 0.58$ & $8.43 \pm 0.24$ & 0.0001 \\
\hline Final Score & $79.65 \pm 9.38$ & $83.54 \pm 7.59$ & $86.14 \pm 8.42$ & $88.70 \pm 7.56$ & 0.0001 \\
\hline
\end{tabular}

Table 4: Harris hip score according to AO classification.

\begin{tabular}{|lll|} 
A0 type & $\begin{array}{l}\text { Harris hip } \\
\text { score at 5 year } \\
\text { (mean) }\end{array}$ & $\begin{array}{l}\text { At 5-year follow-up } \\
\text { good/excellent result } \\
(\%)\end{array}$ \\
\hline A1 & $92.50 \pm 2.43$ & 91 \\
\hline A2 & $86.21 \pm 3.58$ & 86 \\
\hline A3 & $75.76 \pm 8.81$ & 70 \\
\hline
\end{tabular}
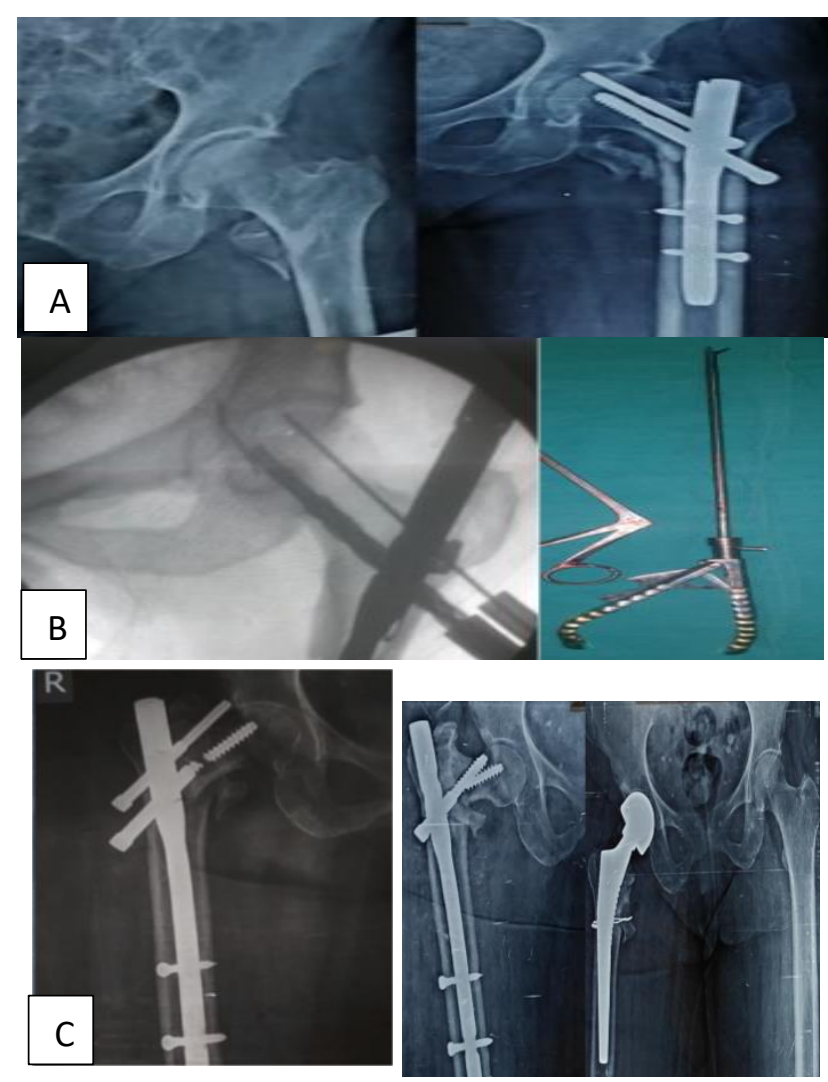

Figure 5: Complications occurred (A) $\mathrm{Z}$ effect, (B) screw breakage $(C)$ guide wire breakage.
Table 5: Surgical complications.

\begin{tabular}{|lll|}
\hline Complications & Number & Percent \\
\hline Surgical site infection & 1 & 0.65 \\
\hline $\begin{array}{l}\text { Screw cut out/screw } \\
\text { breakage }\end{array}$ & 2 & 1.3 \\
\hline Z effect & 1 & 0.65 \\
\hline $\begin{array}{l}\text { Facia-lata pain/screw back } \\
\text { out of implant }\end{array}$ & 2 & 1.3 \\
\hline Varus collapse/malrotation & 1 & 0.65 \\
\hline Union related- & & \\
\hline Mal-union & 1 & 0.65 \\
\hline Delayed & 1 & 0.65 \\
\hline Non-union & 0 & 0 \\
\hline
\end{tabular}

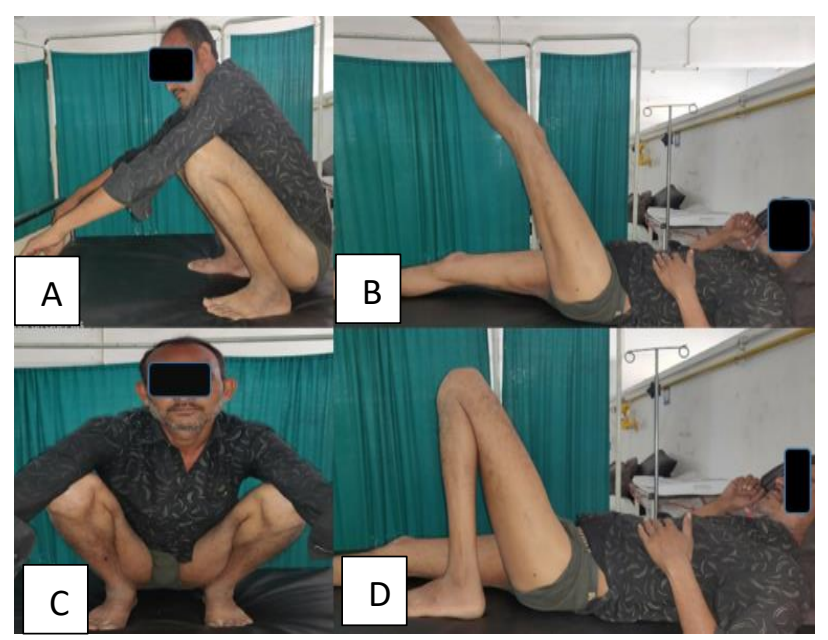

Figure 6: Final Outcome at five years.

\section{DISCUSSION}

Surgical treatment is the best choice to regain normalcy in a quick and better way in patients who sustained inter trochanteric femur fractures. Short trochanteric fixation nail which is one of the most widely used implants in inter trochanteric femur fractures has a shorter lever arm and 
thus allows early weight bearing. The proximal screw of the nail rests over the calcar. and provides a better stability at the fracture site and helps in reducing complications. Our study has tried to determine the long-term outcome of this implant. We believe that if this implant demands technical skills and if used carefully following all the standard guidelines, there are very less chances of implant failure. Internal fixation and early mobilization in inter trochanteric fractures is very crucial as it reduces the risk associated with general health conditions. ${ }^{7}$

All patients who had posteromedial comminution were considered to be having severe type of fracture. The integrity of the lateral femoral wall is very important and has been documented recently. ${ }^{8,9}$ Gotfried showed that in patients with lateral wall fracture, there is a high chance of postoperative collapse at fracture site. ${ }^{8}$ There was a high chance of disability in these patients. Palm et al found that in patients having lateral wall fracture, there was an eight times higher risk of re-operation due to technical failure in patients operated with dynamic hip screw. ${ }^{10}$

The superomedial quadrant of' the femoral head is the weakest part for the implant, and therefore, proper positioning of the screw is important. In our study, the lag screw was inserted close to the subchondral bone, and the anti-rotational hip pin superior to the femoral head. More than $90 \%$ of the lag screws were inserted inferior to the centre of the femoral head with and optimal depth achieving rigid fixation. ${ }^{11}$

In a study done by Koyuncu et al they reported mechanical failures in $17.7 \%$ patients after fixation with proximal femoral nail. ${ }^{12} 9.2 \%$ patients underwent revision procedure for mechanical complications, which was high when compared to our study $(5.92 \%)$. They finalized that the quality of fracture reduction is an important factor that affects the revision rate.

In study of Simmermacher et al overall technical failure rate was only $4.6 \%$, in a series of 191 fractures (of which 170 were unstable) and no patients of fracture below the tip of implant or bending/breakage of the implant. ${ }^{13}$

In our study $1.3 \%(n=2)$ patients of neck screw cutout/breakage occurred. Smeets et al investigated and found that the incidence of $\mathrm{z}$ effect in the operated patients was $9 \%(\mathrm{n}=0) ; 6$ out of $7 \mathrm{z}$-effects occurred in the short nail group which is quite high as compared to our study which had $0.65 \%(n=1) .{ }^{14}$ In the end, they also concluded that the nail length was not associated with the development of a z-effect; lag screws migration is common after intramedullary nailing and is a risk factor for re surgery.

In a prospective study done by Paul et al on 58 patients with final cohort of 30 patients, results showed that fracture type (stable or unstable) significantly predicted telescoping. ${ }^{15}$ The average Harris hip score was 89 , which is similar to our study and concluded that satisfactory functional outcomes with near-normal gait restoration can be achieved in cases of inter-trochanteric hip fractures with focus on calcar reduction and compression after fixation with TFN.

Techniques described by Chun et al described a technique for percutaneous reduction of sagittal unstable intertrochanteric fractures. ${ }^{16}$ They reduced the fracture using a Steinmann pin as a joystick, and stabilized with a TFN. Percutaneous pinning is less invasive reduction technique and is easy and safe for unstable type of fracture in which closed reduction becomes difficult.

Some authors concluded that implant needs to be chosen according to fracture type. Reindl et al did a prospective randomized control trial in unstable intertrochanteric femur fracture managed with both intramedullary implant and extramedullary implant and concluded that there was better radiographic outcome with intramedullary implant with no significance in improved functional outcomes. ${ }^{17}$

In a survey of fixation device used in intertrochanteric femur fracture conducted in United States among the orthopaedic surgeons and revealed that cephalomedullary nail has a better construct. ${ }^{18}$ Most of the surgeons believe that cephalomedullary nail is easier to use during surgery. It is biomechanically superior to sliding hip screw with better outcomes.

The newer concept suggests that augmentation of intramedullary nailing using cerclage wire and lag screws for lateral wall reconstruction in unstable intertrochanteric femur fractures resulted in good radiological and functional outcome; reducing complications and it requires little additional operating time with minimal blood loss and soft tissue injury. ${ }^{19}$ Good/excellent results are seen with use of TFN for inter-trochanteric fractures of femur on long term follow up. In comparison with other studies our outcomes are similar but we had lesser complications.

In our study, we have also found that if all the steps of the surgical procedure and implant fixation are followed step by step, the chances of complications drastically reduce. Even a small error in one of the steps during surgery may lead to major complications for the patient.

We also found that this implant is not the perfect choice for fixation in all types of inter trochanteric femur fractures. The implant choice can be decided as per the condition of the patient, type of fracture. Pre-operative planning can make a big difference and significantly help in smooth working and better outcome.

\section{CONCLUSION}

TFN is an optimum implant for the internal fixation of both stable and unstable intertrochanteric fractures with advantages of stable fixation, perfect reduction, early weight bearing and ambulation, lesser number of days in hospital, significantly better rate of union and early start to normal routine lifestyle. There are some complications 
related to the implant like $\mathrm{z}$ effect, delayed union, screw back-out/breakage, varus collapse but still if the technique used is proper, the results are significantly better as compared to various other implants available for treating inter trochanteric femur fractures. Younger age, stable fracture, less surgical time, active mobile patients, stable vitals, better post-operative rehabilitation are all positive indicators for a better functional outcome.

\section{ACKNOWLEDGEMENTS}

Authors would like to thank all the patients without whose participation this article would not have been possible. We would also like to thank all our department staff members who helped us in some or the other way in making of this article.

\section{Funding: No funding sources}

Conflict of interest: None declared

Ethical approval: The study was approved by the institutional ethics committee of Sri Aurobindo Medical College and PG Institute, Indore, Madhya Pradesh.

\section{REFERENCES}

1. Knobe M, Gradl G, Ladenburger A, Tarkin IS, Pape HC. Unstable Intertrochanteric Femur Fractures: Is There a Consensus on Definition and Treatment in Germany? Clin Orthop Relat Res. 2013;471(9):283140.

2. Boyd HB, Griffin. Classification and treatment of trochanteric fractures. Arch surg. 1949;58(6): 853-66.

3. Bhandari M, Schemitsch E, Jonsson A, Zlowodzki M, Haidukewych GJ. Gamma nails revisited: gamma nails versus compression hip screws in the management of intertrochanteric fractures of the hip: a meta-analysis. J Orthop Trauma. 2009;23:460-4.

4. Halder SC. The gamma nail for peritrochanteric fractures. J Bone Joint Surg. 1992;74-B:340-4.

5. Fogagnolo F, Kfuri Jr M, Paccola CA. Intramedullary fixation of pertrochanteric hip fractures with the short AO-ASIF proximal femoral nail. Arch Orthop Trauma Surg. 2004;124:31-7.

6. Muller ME, Nazarian S. Classification of fractures of the femur and its use in the A.O. index (author's transl). Rev Chir Orthop Reparatrice Appar Mot. 1981;67:297-309.

7. Harris WH. Traumatic arthritis of the hip after dislocation and acetabular fractures: treatment by mold arthroplasty. An end-result study using a new method of result evaluation. J Bone Joint Surg Am. 1969;51:737-55.

8. Gotfried Y. The lateral trochanteric wall: a key element in the reconstruction of unstable pertrochanteric hip fractures. Clin Orthop. 2004;425:82-6.

9. Haidukewych GJ, Israel TA, Berry DJ. Reverse obliquity fractures of the intertrochanteric region of the femur. J Bone Joint Surg Am. 2001;83:643-50.

10. Palm H, Jacobsen S, Sonne-Holm S, Gebuhr P. Integrity of the lateral femoral wall in intertrochanteric hip fractures: an important predictor of a re-operation. J Bone Joint Surg Am. 2007;89:4705.

11. Brown TD, Ferguson AB Jr. Mechanical property distributions in the cancellous bone of the human proximal femur. Acta Orthop Scand. 1980;51:429-37.

12. Koyuncu S, Altay T, Kayalı C, Ozan F, Yamak K. Mechanical failures after fixation with proximal femoral nail and risk factors. Clin Interv Aging. 2015;10:1959-65.

13. Simmermacher RKJ, Bosch AM, Van der Werken C. The AO/ ASIF- Proximal femoral nail: a new device for the treatment of unstable proximal femoral fractures. Injury. 1999;30(5):327-32.

14. Smeets SJM, Kuijt G, Van Eerten PV. Z-effect after intramedullary nailing systems for trochanteric femur fractures. Chin J Traumatol. 2017;20(6):333-8.

15. Paul O, Barker JU, Lane JM, Helfet DL, Lorich DG. Functional and radiographic outcomes of intertrochanteric hip fractures treated with calcar reduction, compression, and trochanteric entry nailing. J Orthop Trauma. 2012;26(3):148-54.

16. Chun YS, Oh H, Cho YJ, Rhyu KH. Technique and Early Results of Percutaneous Reduction of Sagittally Unstable Intertrochateric Fractures. Clin Orthop Surg. 2011;3(3):217-24.

17. Reindl R, Harvey EJ, Berry GK, Rahme E. Canadian Orthopaedic Trauma Society (COTS). Intramedullary Versus Extramedullary Fixation for Unstable Intertrochanteric Fractures: A Prospective Randomized Controlled Trial. J Bone Joint Surg Am. 2015;97(23):1905-12.

18. Niu E, Yang A, Harris AH, Bishop J. Which Fixation Device is Preferred for Surgical Treatment of Intertrochanteric Hip Fractures in the United States? A Survey of Orthopaedic Surgeons. Clin Orthop Relat Res. 2015;473(11):3647-55.

19. Kulkarni SG, Babhulkar SS, Kulkarni SM, Kulkarni GS, Kulkarni MS, Patil R. Augmentation of intramedullary nailing in unstable intertrochanteric fractures using cerclage wire and lag screws: a comparative study. Injury. 2017;48(2):S18-S22.

Cite this article as: Shukla R, Jain A, Mahajan P, Jain R. Confounding variables affecting long term results of standard two screw cephalomedullary nail in intertrochanteric fractures of femur. Int J Res Orthop 2021;7:103-9. 